\title{
THE IMPACT OF LEGISLATION ON CHILDHOOD SEXUALITY IN SOUTH AFRICA
}

\author{
Rushiella Songca
}

BA LLB LLM LLM LLD

Executive Dean, College of Law

University of South Africa (UNISA)

Michelle Karels

LLB LLM LLD

Senior Lecturer, Criminal and Procedural Law

University of South Africa (UNISA)

\section{SUMMARY}

The purpose of this submission is two-fold. Firstly, it undertakes a socio-legal analysis of child sexuality and sexual behaviour. The goal of the analysis is to confront, albeit synoptically, common-held misperceptions, both legally and socially, on the subject of childhood sexuality. Secondly, the submission considers how legislation and judicial interpretation has responded to the expression of a child's sexuality in South Africa. The legal and judicial analysis is centred on the categorization of age, and queries the wisdom of confining normal, non-deviant sexual development in terms of disparate age classifications as expressed in South African Legislation.

\section{$1 \quad$ INTRODUCTION}

One of the current issues receiving media and legal attention, particularly in South Africa, is the sexuality and sexual behaviour of children. ${ }^{1}$ Central to this attention is the perceived inability of children to understand their sexual development, and the dynamics (social and otherwise) that underpin sexual development in childhood which have concurrently attracted debate.

The sexuality of children and the changing norms of adolescent sexual behaviour provoke much debate amongst lay adults and professionals dealing with adolescent sexuality. Their reactions to adolescent sexuality range from complete denial or censor, to acceptance that modern societies recognise freer notions of childhood sexual behaviour. Many contemporary societies acknowledge that sexual experimentation among adolescents is

The word "children" for the purposes of this submission refers to adolescents and the words children and adolescents are used interchangeably. 
part of normal human development. ${ }^{2}$ Some researchers are of the view that childhood sexuality entails other factors that have nothing to do with the sexuality of children per se, or their human development. ${ }^{3}$ Lee et $a l^{4}$ for example, informs us that most adults still subscribe to the notion of the "virginal" child, hence they regard children as innocent and naïve and incapable of engaging in sexual activities. ${ }^{5}$ Moreover, Lee argues that the sexuality of children sometimes has moral overtones in that some adults view children's sexuality as a reflection of the moral health of society, and at times advocate for the regulation of these behaviours. ${ }^{6}$ Regardless of these opposing views, the authors agree with researchers who state the need for adults and professionals to establish what sexuality means for children themselves, and further support the view that children should be allowed to exercise their own social agency. ${ }^{7}$ The authors are of the view that the conflicting views expressed by adults have influenced the manner in which they respond to children's expressions of desire, curiosity and sexual behaviour. Legislation and judicial interpretation follow suite. The divergent opinions and legislative restrictions problematize the discourse on the sexuality of children from a social and legal perspective. ${ }^{8}$

Until very recently, South African law did not explicitly affirm children's rights in respect of their sexuality. ${ }^{9}$ Inferences could, however, be drawn from legal provisions that focused on protecting the legal interests of children when involved in sexual activity. These were largely reactive legislative provisions aimed at protecting children - they did not take into account that sex and sexuality in childhood ${ }^{10}$ are not always a matter of violence or force, but rather a normal developmental process. ${ }^{11}$ The Constitution of the Republic of South Africa, 1996, ${ }^{12}$ for example, provides that everyone has the right to access to health-care services, including reproductive health care. ${ }^{13}$ The applied content of this provision, in respect of children, was later

2 Hoffman "Legal and Social Implications of Adolescent Sexual Behaviour" 19781 Journal of Adolescence 25 27; Flanagan "Making Molehills into Mountains: Adult Responses to Child Sexuality and Behaviour" 20101 Explorations: An E-Journal of Narrative Practice 57-69; and Frayser "Defining Normal Childhood Sexuality: An Anthropological Approach" 20125 Annual Review of Sex Research 173 180-182.

3 See, eg, Lee, Crofts, Salter and McGovern "Let's Get Sexting: Risk, Power, Sex and Criminalisation in the Moral Domain" 2013 2(1) International Journal of Crime and Justice 35.

$20132(1)$ International Journal of Crime and Justice 41.

Frayser 20125 Annual Review of Sex Research 174-175.

Lee et al 2013 2(1) International Journal of Crime and Justice 41.

Frayser 20125 Annual Review of Sex Research 180-181.

8 See De Jong "Sexual Interactions among Siblings and Cousins: Experimentation or Exploitation?" 198913 Child Abuse and Neglect 271; Larsson Sexual Abuse of Children: Child Sexuality and Sexual Behaviour (Export Report: Socialstyrelsen - The National Board of Health and Welfare 2000) 7; and Frayser 20125 Annual Review of Sex Research 173.

9 See the Teddy Bear Clinic for Abused Children, and Resources Aimed at the Prevention of Child Abuse and Neglect $v$ Minister of Justice and Constitutional Development Case 2014 (1) SACR 327 (hereinafter "Teddy Bear").

10 The authors refer here specifically to children/adolescents from the age of 12 and 17 years.

11 Hoffman 19781 Journal of Adolescence 27.

Hereinafter "the Constitution".

13 S 27(1)(a) of the Constitution. 
assimilated into the Choice on Termination of Pregnancy Act. ${ }^{14}$ The latter Act provides that a pregnant minor, who wishes to terminate her pregnancy, should first consult her parents, guardian, family members or friends before the termination procedure. Should she, however, choose not to consult, the termination procedure will not be refused. ${ }^{15}$ The Act is reactive after the fact and highlights some unintended consequences of normal sexual development in childhood. Although the authors do not dispute the necessity of this law, they nevertheless submit that sexual legislation does not address the problematiques of adolescent sexuality and what sexuality or sex means for them and why adolescents engage in these behaviours to begin with.

The previous South African Criminal Law (Sexual Offences and related matters) Amendment Act, ${ }^{16}$ an example of a relatively recent law concerning sexual crimes, explicitly regulated and managed children's sexual behaviours in sections 15 and $16 .{ }^{17}$ However, the Constitutional Court in Teddy Bear declared some of the provisions of the Act unconstitutional, thus resulting in the amendment of sections 15 and 16 of the Sexual Offences Act. The amended Sexual Offences Act remains the main statute in South Africa regulating sexual behaviour of children, as well as sexual misconduct of both children and adults. ${ }^{18}$ Selected provisions of the amended Act are discussed later in this submission.

Below the authors, in meeting the first aim of this submission, consider the development of childhood sexuality from a social-developmental perspective.

\section{DEVELOPMENT OF CHILDHOOD SEXUALITY}

Research ${ }^{19}$ indicates that to better understand children's behaviours, it is important for professionals and adults to educate themselves on the psychosexual development of adolescents. A child's cognitive and biological development is a critical factor in the development of his/her sexuality. Although adolescence is a period of growth, spanning between the ages of 12 and 24 years, this submission relates to children between the ages of 12 16 years of age.

A number of scholars have made various assertions regarding the sexual development of adolescents. Murphy and Ellias, ${ }^{20}$ state that sexual development of children is a process that involves different physical,

\footnotetext{
92 of 1996.

S 5(3).

32 of 2007 (hereinafter "the Sexual Offences Act").

When viewed only as those acts between children between the ages of 12 and 16 years who both consent to the act of intercourse and associated practices.

18 The authors assert that the Act reflects a particular stance to so-called "normal" sexual behaviour between consenting children in the age category between 12 and 16 years, as well as the regulation of criminal conduct involving adults and children.

19 See, eg, De Jong 198913 Child Abuse and Neglect 13; Larsson Sexual Abuse of Children: Child Sexuality and Sexual Behaviour 7 and Frayser 20125 Annual Review of Sex Research 173.

20 "Sexuality of Children and Children with Developmental Disabilities" 2006 118(1) American Academy of Paediatrics 398; and Oswalt "Child Development Theory: Adolescence Summary and Conclusion" http://www.sevencounties.org/poc.view (accessed 2015-08-20).
} 
emotional, cognitive, social, moral, gender-role socialisation and sexual dimensions. They argue that children's perceptions and understanding of sexuality may be influenced by the social mores and practices subscribed to in their communities. Steinberg ${ }^{21}$ is of the view that as children grow they exhibit different desires and express the need to be affirmed, liked or accepted by either their peers or older children. Steinberg is of the view that children reach developmental milestones at different ages. ${ }^{22}$ The lack of a set age at which cognitive development can be seen as complete may lead in some cases to sexual activity taking place in the absence of cognitive and emotional maturity. This may have devastating implications for adolescents. $^{23}$

Frayser ${ }^{24}$ posits that the sexuality of children is a process that manifests itself in different ways as the child goes through the different developmental stages. For example, these stages may include children experiencing sexual feelings or desire, masturbation and other forms of sexual behaviour. He further opines that children are innately sexual beings and experience different sexual feelings as part of their normal human development. These feelings may range from reading on sexual matters to talking about sex and may include conduct such as viewing images containing sexual content. ${ }^{25}$ On the other hand, Oswalt ${ }^{26}$ reminds us that children between the ages of 12-15 years, although sexually active, may lack cognitive and emotional maturity to make sound decisions about their sexual choices.

Children between the ages of 12-15 years are regarded as going through early adolescence. This period in a child's life is regarded as crucial because of the inter-relationship between the child's sexual, cognitive and emotional development. $^{27}$

From the brief discussion above it is clear that the development of sexuality is premised, at least in the social domain, centrally on cognitive development theories. These theories are useful from an academic perspective but say very little of how childhood sexuality is understood. The development of sexual feelings in children is often interpreted from an adult perspective.

\section{ADULT UNDERSTANDING OF CHILDHOOD SEXUALITY}

Literature reveals that adults generally do not understand the sexuality of children. Frayser ${ }^{28}$ professes that this is largely because it is difficult to shift focus from the fact that childhood is regarded as a time of sexual naiveté. The distorted view of children as agents of innocence leads, in some cases,

21 "Cognitive and Affective Development Theory: Adolescence-Summary and Conclusions" 2005 Trends in Cognitive Sciences 69.

Steinberg 2005 Trends in Cognitive Sciences 72.

Steinberg 2005 Trends in Cognitive Sciences 69.

20125 Annual Review of Sex Research 190-192.

Ibid.

http://www.sevencounties.org/poc.view (accessed 2015-08-20).

Ibid.

20125 Annual Review of Sex Research 173. 
to children exploring sex without adult guidance. Frayser ${ }^{29}$ asserts that this robs children of opportunities to understand and be guided by adults about their sexual development and sexual matters.

Larsson ${ }^{30}$ argues that cultural practices may compound problems for children. Most societies regard girls as innocent and as deserving special protection. However, some practices that are meant to protect children, may in fact be disempowering. For example, girls may be discouraged from exploring their bodies or prohibited from discussing sexually related matters. In addition, Larsson notes that children learn, as they interact with other members of society, that sexuality is not value free and that it is influenced by prejudices and a society's social mores. ${ }^{31}$ Some children learn from an early age that sexuality, and matters relating thereto, is a topic that is best kept secret from others; as a result, children are left to learn about sexuality from the media and their peers. The lack of proper parental or adult guidance has led to children at times making poor decisions relating to their sexuality or the responsibilities that come with being sexually active. ${ }^{32}$

In an attempt to understand the sexuality of children, researchers and professionals working with children categorise children's sexual behaviours as either normal or deviant. Law and policy respond similarly. Nevertheless, there are no universally accepted criteria available for distinguishing between abusive sexual contact, said to be deviant, and normal sexual exploratory behaviour. ${ }^{33}$ This distinction is, however, relevant in South African society and law, and thus briefly considered below.

\section{4 "NORMAL" AND DEVIANT SEXUAL BEHAVIOUR IN CHILDREN}

Although social frameworks may influence and shape children's sexuality and behaviours, some researchers such as De Jong, ${ }^{34}$ are of the view that sexuality of children begins at an early age and continues until adulthood. In their view development progresses through various stages and is influenced by the environment in which the child lives and is exposed to.

Sociologists view sexuality as a social construct. In terms of this view, the social system, along with economic, religious, medical, and cultural factors, determine the position held by society about the nature of sexuality. ${ }^{35}$ For sociologists, each society constructs and shapes norms and practices that are considered acceptable forms, or expressions of sexuality. For example, the sexuality of boys and girls develops on this basis and is subject to the dictates of the society of which they are a part. As a result, assumptions on sexuality by society are transmitted to its members. ${ }^{36}$ Children ponder upon

\footnotetext{
20125 Annual Review of Sex Research 207.

Sexual Abuse of Children: Child Sexuality and Sexual Behaviour 32-33.

Larsson Sexual Abuse of Children: Child Sexuality and Sexual Behaviour 33.

Ibid; see also Teddy Bear 342.

De Jong 198913 Child Abuse and Neglect 277.

Ibid; and Frayser 20125 Annual Review of Sex Research 179-182.

Ibid.

Ibid.
} 
their social contexts in search for hints of what constitutes normal sexual behaviour. ${ }^{37}$ Therefore, naturally, children's sexual behaviours are also measured against these societal norms. ${ }^{38}$

Given the complexity of child sexual abuse and the different perceptions around childhood sexuality, researchers and professionals dealing with children struggle to reach a common understanding of what constitutes abuse (or deviant sexual behaviour) and accepted (normal) sexual development in childhood. Lee et $a l^{39}$ assert that literature and research, which seek to explain childhood sexuality, reveal that views are informed by paternalistic undertones and reflect adult society's moral biases, as well as a need to save children from their own uninformed and immature sexual desires. We submit that law responds in a similar fashion. Indeed children require protection from abuse, which is natural and necessary, but in this process acceptable sexual development is cast aside and left to social development.

In trying to understand children's sexuality, both Larsson $^{41}$ and Flanagan ${ }^{42}$ posit that researchers make a distinction between normal, or age appropriate behaviours on one hand, and deviant (abnormal/abusive) behaviours on the other hand. ${ }^{43}$ This approach to sexuality has resulted in the regulation and development of guidelines, which stem from the past. Thus, in determining whether children's behaviours are normal or exploratory and hence part of their sexual experimentation, an inquiry of possible sexual deviance among children may include the following: ${ }^{44}$

(i) The age difference between the participants; the so-called "close-in-age" test. Here the inquiry focuses on the age differences between children. Some researchers have argued that, if the age difference is two years or more, exploitation is likely. ${ }^{45}$ For example, this assumption is clear in instances where one child is 12 years old and the other 16 . In such a case, any consensual sexual activity will be regarded as deviant. Section $52(2)(b)$ of the previous Sexual Offences Act ${ }^{46}$ makes provision for statutory defences that are relevant to a charge of rape or statutory assault. It stated that whenever an accused person is charged with an offence under section 16 , it was a valid defence to such to argue that

37 Shoveller "Socio-Cultural Influences on Young People's Sexual Development" 2004 Social Science \& Medicine 473.

38 Larsson Sexual Abuse of Children: Child Sexuality and Sexual Behaviour 33.

$3920132(1)$ International Journal of Crime and Justice 37.

40 The authors demonstrate later in this submission that the handling of sexual development by $s 15$ and 16 of the Sexual Offences Act remains flawed in its observation of normal childhood sexual development.

41 Sexual Abuse of Children: Child Sexuality and Sexual Behaviour 33.

4220101 Explorations: An E-Journal of Narrative Practice 72.

43 Deviant sexual behaviours manifest themselves when something happens to interrupt what is considered the normal sexual development of a child/adolescent, eg, where a child has been sexually abused he may exhibit sexual behaviours that show that something age inappropriate has happened in the child's life. Deviant behaviours counter a society's norms on child sexuality.

44 It should be noted that these guidelines have found expression in the Sexual Offences Act.

45 De Jong 198913 Child Abuse and Neglect 277.

46 Of the unamended Sexual Offences Act; see discussion below regarding the changes in the Sexual Offences Amendment Act. 
both the accused persons were children and the age difference between them was not more than two years at the time of the commission of the offence. $^{47}$

(ii) In terms of these guidelines, it is also important to understand why adolescents engage in sexual behaviours. Some researchers ${ }^{48}$ opine that children are motivated by curiosity and a need to better understand their bodies; they remind us that sexuality is part of a process of human development. Thus, adolescents express their sexuality in an attempt to familiarise and explore their worlds and their bodies and to know more about themselves, others and relationships. For example, such escapades are playful and involve games such as "show me yours and I'll show you mine" or "mother and father". ${ }^{49}$

Regardless of the above guidelines, Larsson ${ }^{50}$ is of the view that researchers still struggle to describe, or agree, on what constitutes normal sexual behaviour amongst children. For instance, some researchers assert that sexual behaviour by children is a result of a natural, human, biological and psychological developmental process. Other researchers are of the view that the sexual behaviour of children can be regarded as normal and typical when judged within the environments in which they live. ${ }^{51}$ For example, a behaviour is normal if it is regarded as such by the majority of people, or the population of a particular place or society - viewed as such, normality in consequence of a statistical factor. ${ }^{52}$ Furthermore, in some instances behaviour is regarded as normal if it promotes health. ${ }^{53}$

Larsson ${ }^{54}$ asserts that behaviours are social constructs, value laden and informed by how people perceive one another and themselves. In the Teddy Bear case $^{55}{ }^{5}$ the Constitutional Court observed that the majority of children in South Africa between the ages of 12 and 16 years are already engaging in a variety of sexual behaviours, some of which are regarded as normal. The Court noted that these behaviours range from kissing to masturbation to intercourse.

Cultural practices also influence peoples' assumptions about sexuality; hence, behaviours that are regarded as normal in one culture may be seen as deviant, or as abusive in other cultures. ${ }^{56}$ The contradicting views on virginity testing and genital mutilation serve as good examples. ${ }^{57}$

47 It should be noted that this defence is not applicable if the accused person is related to the child victim "within the prohibited degrees of blood, affinity or an adoptive relationship".

48 Flanagan 20101 Explorations: An E-Journal of Narrative Practice 59-60; Frayser 20125 Annual Review of Sex Research 192; and see also Teddy Bear's case 342-343.

49 Flanagan 20101 Explorations: An E-Journal of Narrative Practice 60.

50 Sexual Abuse of Children: Child Sexuality and Sexual Behaviour 12.

51 See also Frayser 20125 Annual Review of Sex Research 192; and Flanagan 20101 Explorations: An E-Journal of Narrative Practice 59.

52 Larsson Sexual Abuse of Children: Child Sexuality and Sexual Behaviour 12.

53 Larsson Sexual Abuse of Children: Child Sexuality and Sexual Behaviour 13.

54 Sexual Abuse of Children: Child Sexuality and Sexual Behaviour 23.

343-344.

56 Larsson Sexual Abuse of Children: Child Sexuality and Sexual Behaviour 13-14.

57 Van der Poll "The Impact of Traditional Sex Practices on the Construction of Female Sexuality: An African Human Rights Perspective" 2009 13(2) Law, Democracy \& 
The discussion above illustrates that children's sexual behaviours are informed partly by their own curiosities, and later gain meaning as they interact with their environments such as the media. Further, their behaviours are influenced by socio-economic and cultural norms, societal assumptions and expectations.

The authors are of the view that childhood sexual behaviour is informed by the contradictions engendered by their surroundings. For example, children are regarded as vulnerable members of society that need protection. This protectionist approach to children has resulted in the regulation of children's behaviour and the promulgation of laws to protect children. These interventions, whilst necessary in cases of deviant behaviour, have unwittingly resulted in controversy and uncertainty regarding non-deviant sexual development in childhood, at least from a legal perspective. In the Teddy Bear case ${ }^{58}$ the Constitutional Court argued that the effect of criminalising under-age sex would under certain circumstances result in feelings of guilt, shame, embarrassment and regret. Thus, children may have negative feelings towards sexual matters and these feelings may continue to exist into adulthood. For example, Lee et al ${ }^{59}$ opine that the problem of childhood sexuality, and measures to suppress or regulate it, emerged in the late $17^{\text {th }}$ to early $18^{\text {th }}$ Century. Views around children ranged from them being victims of uncontrolled sexual fantasies and a preoccupation with masturbation. History reveals that indifference towards child rearing and, by extension, their sexuality, was the dominant attitude in Western civilisations in the $13^{\text {th }}$ century. ${ }^{60}$

Lee states that by the $18^{\text {th }}$ Century, parent-child relations improved. This century also marked the emergence of moderators and reformers who began to take an interest in children, including their sexuality. ${ }^{61}$ By the $20^{\text {th }}$ century, experts ranging from clinicians, and psychiatrists to lawyers and social workers dominated the discourse. These professionals played a central role in mainstreaming sex education into school curriculums. ${ }^{62}$ Nevertheless, they all held different views about the sexuality and sexual behaviours of children. For example, Wigmore, ${ }^{63}$ a former professor at Harvard University, played a significant role in perpetuating the tradition of scepticism towards victims of sexual offences. Commenting on the sexual behaviours of girls and women, he states:

"Modern psychiatrists have amply studied the behaviour of errant young girls and women before the courts in all sorts of cases. Their psychic complexes are multifarious, distorted partly by inherent defects, partly by diseased

Development $13-6$. See also Moodley “Customary Initiation Rites and the Children's Act 38 of 2005' 200823 SAPR/L 65 65-68.

58 See fn 9 above.

$5920132(1)$ International Journal of Crime and Justice 41-42; see also Songca Aspects of Sexual Abuse of Children: A Comparative Study (LLD Pret 2003) 43.

60 Lee et al 2013 2(1) International Journal of Crime and Justice 41; see also Songca Aspects of Sexual Abuse of Children: A Comparative Study 43; see further Songca "Evaluation of Children's Rights in South African Law: The Dawn of An Emerging Approach to Children's Rights?" 2011 CILSA 338 341-343.

61 Songca Aspects of Sexual Abuse of Children: A Comparative Study 43.

62 Lee et al 2013 2(1) International Journal of Crime and Justice 41.

63 Treatise on the Anglo-American System of Evidence in Trials at Common Law (1923) 459. 
derangements or abnormal instincts, partly by bad social environments, partly by temporary physiological or emotional conditions ...

Furthermore, renewed public awareness of sexual abuse in the $20^{\text {th }}$ and $21^{\text {st }}$ centuries led to the reconceptualization of childhood. The social construction of children during these centuries was informed by increased concern relating to children as victims and perpetrators of abuse. ${ }^{65}$ Many societies responded to these concerns by introducing various intervention strategies aimed at protecting and preventing harm to children, such as educational campaigns, legislation, intensified morally laden presumptions and assumptions of children, most of which did not necessarily reflect the lived experiences of children. ${ }^{66}$ Regulation of sexual behaviour was counterproductive because it resulted in a veil of silence drawn over the sexuality of children.

Resultantly adult responses to the sexual behaviours of children vary. For instance, children are in most cases discouraged from exploring their own bodies and from talking about sexual matters with their parents. At times, there is a deliberate deficit of information whereby parents avoid talking to children about sexual matters that make them uncomfortable. ${ }^{67}$ This gap in information results in children seeking guidance elsewhere and this may result in children making incorrect decisions or choices that may have farreaching consequences for them. ${ }^{68}$ In addition, some cultural practices compound matters. For example, in some cultures sexuality is distorted, hence, women are sometimes circumcised in order to prevent them from enjoying and embracing their sexuality.

This submission has thus far presented a brief social perspective on childhood sexuality. The social factors are, however, of little value unless transposed into law and developed through judicial interpretation. The remainder of this submission considers childhood sexuality from the legal perspective and questions the logic of some of its tenets.

While it is trite that the Constitution views children as all persons under the age of 18 years, the position is not uniformly embraced in legislation. Children are given various interpretations under numerous legislative instruments and this conflagration of age categorisations is leading to a situation where legal certainty is sacrificed for the sake of the overinclusiveness of the rule of law. Below, the authors briefly survey selected examples of current age categorisation in various legal provisions.

64 Wigmore Treatise on the Anglo-American System of Evidence in Trials at Common Law 740 .

65 Lee et al 2013 2(1) International Journal of Crime and Justice 41.

66 Lee et al 2013 2(1) International Journal of Crime and Justice 42.

67 See Frayser 20125 Annual Review of Sex Research 207.

68 Durojaye "Realizing Access to Sexual Health Information and Services for Adolescents Through the Protocol to the African Charter on the Rights of Women' 200916 Wash \& Lee J Civil Rts \& Soc Just 135 147-148. 


\section{AGE, SEX AND LAW}

\section{Sexual Offences Act}

According to the Sexual Offences Act a child is considered mature enough to consent to sex at the age of 16 years. This, however, is not the end of the age-based regulation of sexual conduct by the Act. Under the previous section 15 and 16 of the Sexual Offences Act, children aged 12 to 16 years were proscribed from engaging in consensual sexual conduct with their peers. Such acts varied from kissing to engaging in other forms of sexual intimacy, including sexual intercourse. The Constitutional Court addressed the constitutionality of these provisions in the Teddy Bear case alluded to earlier.

The enquiry in Teddy Bear $^{69}$ was whether it was constitutional to criminalise consensual sexual conduct between consenting adolescents, defined as being between the ages of 12 and 15 years. Until the Teddy Bear case, sections 15 and 16 of the Sexual Offences Act criminalised a wide range of consensual sexual behaviours between children of a certain age. The applicants, in the Court a quo, lodged an application that sought to challenge the constitutional validity of certain sections of the Act. The High Court held that the provisions of sections 15 and 16 of the Act were unconstitutional and should be amended. It requested the Constitutional Court to confirm the judgment and to pronounce on the constitutionality of these provisions.

The Constitutional Court held that the provisions of sections 15 and 16 of the Sexual Offences Act were unconstitutional and violated constitutional rights relating to human dignity, ${ }^{70}$ privacy ${ }^{71}$ and the best interest of the child. $^{72}$

In considering the provisions relating to human dignity, Khampepe $\mathrm{J}$ affirmed that the right to dignity is a cornerstone of constitutional democracy and that the dignity provision affirms the self-worth a person has as an individual regardless of his or her age. This includes the value attached to the decisions taken by such an individual. ${ }^{73}$ The Court reiterated the importance of children's right to dignity and argued that this right was innate in as far as children are concerned and not dependent on the rights of their parents. In South Africa, recognising the dignity of children is important, given our past history wherein children bore the brunt of violence during the apartheid era and were not given a voice to assert agency or individual rights' mandate.

Khampepe $\mathrm{J}$ argued that the criminalisation of consensual sexual conduct was exacerbated by section 41 of the then Sexual Offences Act, which

70 S 10 provides that everyone has inherent dignity and to have their dignity respected and protected.

$71 \mathrm{~S} 14$ recognises the right of all persons to privacy.

$72 \mathrm{~S} 28(2)$ states that a child's best interests are of paramount importance in every matter concerning the child.

73 Per Khampepe J, in Teddy Bear 344-345.
} 
required the names of persons who had committed offences in terms of section 15 and 16 to be placed in the Sexual Offenders Register. The Court noted the devastating consequences of placing a person's name on the register. ${ }^{74}$ The unamended Act defined categories of sexual offenders and prohibited them from working with, or having access to children and persons with mental disabilities. ${ }^{75}$ In addition, persons whose particulars are listed in the register are prohibited from employment and certain forms of activity. For example, they may not become foster parents, caregivers or adoptive parents of a child. ${ }^{76}$ Based on the above, Khampepe $\mathrm{J}$ judged that sections 15 and 16 of the Sexual Offences Act limited children's rights to dignity.

In evaluating children's rights to privacy, the Court was of the view that the right-to-privacy clause articulated in the Constitution applied to everyone, including adolescents. Khampepe J emphasized that sections 15 and 16 both applied to the most intimate spheres of personal relationships and as such implicated the constitutional right to privacy. In this regard, the Court took the view that the prohibition went to the heart of the right to privacy and was concerned that the criminalisation of conduct regarded as a normal rite of passage to adulthood made serious inroads into the personal lives of adolescents. ${ }^{77}$ The Court held that the sections in question violated adolescent's right to privacy.

Khampepe's point of departure in giving content to the provisions of section 28(2) of the children's rights clause in as far as it related to the impugned provisions, was to argue that the evidence before the Court showed that the existence of sections 15 and 16 would discourage adolescents from seeking help in relation to sexual matters and they would not make use of structures that are intended to assist them. ${ }^{78}$ The Court argued that the reporting provisions under section 54(1) of the Sexual Offences Act would have negative impacts on families in that children would be discouraged from discussing sexual matters with their parents and/or professionals. ${ }^{79}$ The Court contended that rendering sexuality of children invisible impacts directly on their sexual development. Importantly, the Court asserted that the implementation of these provisions might result in imprisonment or diversion processes against children who were essentially expressing non-deviant sexual development. ${ }^{80}$

Given the above, the Constitutional Court, after evaluating the evidence, concluded that the provisions of sections 15 and 16 would not be beneficial and protective of adolescents engaging in sexual activities. Consequently, the Court held that the provisions encroached on the best-interest principle.

\footnotetext{
Teddy Bear 346 par 57

Shenxane "Learn More about Your Criminal Justice System: Part 10 - National Register for Sex Offenders" 2012 Servamus 50.

76 See s 41(1)(a)-(d).

77 Teddy Bear 347 par 60.

78 The same sentiments are expressed by other researchers, such as Frayser, Larsson and others. See discussion above.

79 Teddy Bear 341 par 43 and 342 par 47; and see also Frayser 20125 Annual Review of Sex Research 204-205 and 207-209.

80 The Child Justice Act 75 of 2008.
} 
The Court measured sections 15 and 16 against section 36 of the Constitution in coming to the above conclusion. The Court first examined the importance of the limitation. It acknowledged the importance of protecting children from the consequences of prematurely engaging in consensual sexual conduct and the effect this might have on their development. Nevertheless the Court was of the view that the provisions in question had far-reaching consequences for children.

In evaluating the nature and extent of the limitation, the respondents relied on "prosecutorial discretion" and the availability of diversion measures in the Child Justice Act 75 of 2008 to justify the limitation of constitutional rights. The Court argued that the existence of diversion processes were not in themselves helpful in that children would still be exposed to the effects of the criminal justice system earlier in the process if section 15 and 16 were left unamended. ${ }^{81}$

The Court further noted that the respondents had failed to provide evidence to support the claim that the implementation of sections 15 and 16 would deter children from engaging in sexual conduct and thus avoid the risks associated with premature sexual activity. Hence, the Court held, the respondents had failed to show a rational link between the impugned provisions and their stated purpose which therefore could not be saved by the limitation clause. ${ }^{82}$

The authors are of the view that the decision in the Teddy Bear case is significant because it resonates with international trends and research on the sexual development of children. ${ }^{83}$ In the main, the Court accepted expert evidence that articulated the need for children to explore their sexuality. The expert evidence in Teddy Bear confirmed other research findings that adolescents' expressions of sexuality - such as masturbation and kissing are a part of their sexual and biological development. Expert evidence provided in Court also supports the view that ${ }^{84}$ children are innately sexual beings and they should be allowed to exercise their social agency as long as their behaviours are not harmful or deviant.

The amended position is thus that children over the age of 16 years may validly consent to sex; children between the ages of 12 and 15 may consent in certain circumstances, and children below the age of 12 years cannot give valid consent to sexual acts whether penetrative or non-penetrative.

\footnotetext{
See Teddy Bear 352.

Teddy Bear 353-354.

See Teddy Bear 342-343; and see further discussion earlier in submission.

84 See De Jong 198913 Child Abuse and Neglect 271; Larsson Sexual Abuse of Children: Child Sexuality and Sexual Behaviour 7; Frayser 20125 Annual Review of Sex Research 173; and Lee et al 2013 2(1) International Journal of Crime and Justice 35.
} 


\section{The scope and content of the amended section 15 and 16 of the Sexual Offences Act}

According to the preamble of the Amendment Act, adolescents must be discouraged from prematurely engaging in sexual conduct, which has the potential to harm their development. The premise of the amendment is to affect this aim, but to do so in a manner that respects the dignity of children, in relation to their sexual choices in the absence of force or duress. This aim is quoted in the preamble as being "legitimate and important". It is, however, trite that the position under the previous Sexual Offences Act was untenable because it conferred criminal status on children and permitted their inclusion on the National Register of Sex Offenders. Both of the aforementioned are contrary to the best interest-of-the-child standard as the paramount concern of section 28 of the Constitution of the Republic of South Africa, 1996.

The Amendment Act aims to achieve the dual purpose of discouraging potentially development-delaying consensual sexual conduct between persons between the ages of 12 and 15 years, and respecting the dignity of children, through a reimagined approach to the now disused crimes of statutory rape and statutory sexual assault.

Section 2 of the Amendment Act substitutes section 15 of the Sexual Offences Act to the effect that:

(i) A person who commits an act of penetration ${ }^{85}$ with a child between the ages of 12 and 16 years, with the consent of the child, is guilty of consensual sexual penetration of a child; unless:

(ii) the person committing the act of penetration is between the ages of 12 and 16 years of age; or

(iii) the person committing the act of consensual sexual penetration is 16 or 17 years of age, and the difference between the actor and the child giving consent is not more than two years.

The above decriminalises consensual sexual penetration amongst children at or over the age of 12 years and fewer than 16 years and provides an escape valve for those at or over the age of 16 years, where the sexual partner is fewer than two years younger in age. Where there is more than 2 years' age difference between the perpetrator and the consenting partner the act, even where consensual, is unlawful. Where, however, one party is 16 or 17 years of age, and the age difference between him or her, and the other party, is more than 2 years, the Director of Public Prosecution must consider whether to prosecute the older party. The Director of Public

85 "Sexual penetration" includes any act which causes penetration to any extent whatsoever by -

(a) the genital organs of one person into or beyond the genital organs, anus, or mouth of another person;

(b) any other part of the body of one person or, any object, including any part of the body of an animal, into or beyond the genital organs or anus of another person; or

(c) the genital organs of an animal, into or beyond the mouth of another person, and "sexually penetrates" has a corresponding meaning. 
Prosecution may delegate his or her authority to decide on prosecution or a return of nolle prosequi.

Section 3 of the Amendment Act substitutes section 16 of the Sexual Offences Act to the effect that:

(i) A person who commits an act of sexual violation ${ }^{86}$ with a child between the ages of 12 and 16 years, with the consent of the child, is guilty of consensual sexual violation with a child; unless:

(ii) the person committing the act of sexual violation and the consenting party were between the ages of 12 and 16 years of age; or

(iii) the person committing the act of sexual violation is 16 or 17 years of age and the difference between the actor and the child giving consent is not more than two years.

The above decriminalises consensual sexual violation amongst children at or over the age of 12 years and fewer than 16 years and provides an escape valve for those over the age of 16 years, where the sexual partner is fewer than two years younger in age. Where one party is 16 or 17 years of age, and the age difference between him or her, and the other party, is more than 2 years, the Director of Public Prosecution may authorise a prosecution against the older party. The Director of Public Prosecution may delegate his or her authority to decide on prosecution or a return of nolle prosequi.

The above amendment of section 15 and 16 of the Sexual Offences Act still imputes criminal liability on an adult who engages in consensual sexual penetration or violation with a person between the ages of 12 and 16, and on a child who is more than 2 year older than the consenting party, where the perpetrator is no longer an adolescent (that is, 16 or 17 years of age). While the amendments may appear prima facia to satisfy the Court's conclusion in the Teddy Bear case, we submit that it may have some unintended

86 "Sexual violation" includes any act which causes -

(a) direct or indirect contact between the -

(i) genital organs or anus of one person or, in the case of a female, her breasts, and any part of the body of another person or an animal, or any object, including any object resembling or representing the genital organs or anus of a person or an animal;

(ii) mouth of one person and -

(aa) the genital organs or anus of another person or, in the case of a female, her breasts;

(bb) the mouth of another person;

(cc) any other part of the body of another person, other than the genital organs or anus of that person or, in the case of a female, her breasts, which could -

(aaa) be used in an act of sexual penetration;

(bbb) cause sexual arousal or stimulation; or

(ccc) be sexually aroused or stimulated thereby; or

(dd) any object resembling the genital organs or anus of a person, and in the case of a female, her breasts, or an animal; or

(iii) mouth of the complainant and the genital organs or anus of an animal;

(b) the masturbation of one person by another person; or

(c) the insertion of any object resembling or representing the genital organs of a person or animal, into or beyond the mouth of another person, but does not include an act of sexual penetration, and 'sexually violates' has a corresponding meaning. 
consequences, which the Sexual Offences Act and Amendment Act do not address.

\section{Exploring the consequences of the amended section 15 and 16}

Where two children are, for example 12 and 15 years of age, any act of penetration or sexual violation can be justified under the defences available in the Amended sections 15 and 16. Where, however, the older child exits adolescence and turns 16 the same consensual act(s) has/have the potential to raise criminal liability against the older child. Granted, the Amendment stipulates that prosecution will result only at the discretion of the Director of Public Prosecution, but the implication is that there is the potential for a previously non-criminal act to be converted to a criminal act, at the discretion of the prosecution. The Amendment Act provides no guidance as to how the prosecutorial discretion in these cases is to be exercised. Essentially, if the prosecution proceeded is against the older child, he or she goes from a position of protection under the best-interest standard to one of stigmatisation and criminalisation. In this event, the offending party will still fall under the procedural tenets of the Child Justice Act 75 of 2008.

No mention is made in the Amendment Act of criminalisation where both children are between the ages of 12 and 16 years, where the consent of the child is obtained through coercion or duress. Naturally, any act in which consent is not given would result under the crime of rape and no justification is available to the perpetrator no matter his or her age. The issue that, however, arises to begin with, is whether consent given by a child between 12 and 16 years of age should be given any legal validity. The legislature, influenced as it were, by the judiciary, seems to have answered this inquiry in the affirmative in section 15 and 16 of the Amendment Act. But we submit, the legislative amendment must be read in line with the provisions of the Constitution, and other legislative instruments having bearing on age categorisation and the best-interest standard. Some of these are explored below.

\section{Age, sexuality and the Children's Act 38 of $2005^{87}$}

Section 1 of the Children's Act defines a child as a person under the age of 18 years of age. This provision is in line with the Constitution and incorporates the protections offered by the children's rights clause. Majority status is attained at reaching the age of 18 years, unless the child marries under the provisions of the Children's Act and Marriage Act 25 of $1961 .{ }^{88}$ When a child marries, however, there is some debate whether this results in the loss of protection under the children's rights clause or the provisions of

87 The Children's Act contains various provisions pertaining to various legal acts and status issues. Here we are concerned only with those provisions pertaining to sexuality and development. Thus we do not discuss, for example, a child's status when, for example, entering into contracts or credit agreements.

88 Read with certain provisions of the common law. 
the Children's Act. A female child may enter a civil marriage under the precepts of common law, read with the Children's Act, between the ages of 15 and 17 years with the consent of her parents. A female between the ages of 12 and 14 years may only marry with the consent of her parents and the Minister of Home Affairs. ${ }^{89}$ In the case of males between the ages of 14 and 17 years the consent of the parents and Minister of Home Affairs is necessary to enter into a civil law marriage. In essence, the common law position that a female child below the age of 12 years and a male child below the age of 14 years cannot into a valid marriage, prevails. It is trite that the child's consent is always a precondition of marriage. At customary law a female child between the ages of 12 and 17 years, and a male child between the ages of 14 and 17 years of age, will require the consent of both the parents and the Minister of Home Affairs, according to section 3 of the Recognition of Customary Marriages Act 120 of 1998. The Civil Union Act 17 of 2006 does not provide any express provision for those below the age of 18 years, but we submit, on the basis of equity, the same age restrictions and categorisations would apply as in the case of civil law marriage. The position in the case of customary law civil unions of children is, however, an area which requires further exploration.

Although the alteration of sex description is not dealt with specifically by the Children's Act, section 129 regulates a child's status with regard to consenting to medical and surgical procedures and we thus deal with the topic here. A child, who has undergone alteration of sex procedures, whether surgically or through medical treatment, may have his/her name changed on the birth register according to the procedures provided therefore by section 27A of the Births and Deaths Registration Act 51 of 1992. The regulation of alteration procedures is determined by the Alteration of Sex Description and Sex Status Act 49 of 2003. Consent to surgical procedures and medical treatment is dealt with by the Children's Act. At the age of 12 years a child, who is of sufficient maturity to understand the risks, benefits and implications of surgery and who is assisted by a parent or guardian, may consent to a surgical procedure. Where under the age of 12 years or over the age of 12 years, but insufficiently mature, the parents' consent is required and the views of the child must be taken into account where appropriate. In the case of medical treatment the same regulations apply with the exception that a sufficiently mature 12-year old does not have to be assisted by a parent or guardian when consenting to medical treatment as is the case when consenting to a surgical intervention. Although no specific provision is provided for refusal, or medical treatment, or surgical intervention, it is logical that a sufficiently mature enough 12-year old can refuse consent. ${ }^{90}$ In the case of sterilisation procedures no person under the age of 18 years may consent to sterilisation unless there are circumstances which would jeopardize the life or well-being of the child. ${ }^{91}$

89 No child may enter into a civil marriage without their consent or be betrothed or offered into marriage by parents - see $\mathrm{s} 17$ and 18 of the Children's Act.

90 See s 129(2) and (3) of the Children's Act as well as s 6(1) of the National Health Act 61 of 2003 and $s$ 12(2) of the Constitution, for the underlying rationale for refusal of medical treatment by a child.

91 See s 2 and 3 of the Sterilisation Act 44 of 1998. If the child requires sterilisation of health reasons consent may be given by a parent or guardian after an independent medical 
Section 129 of the Children's Act is subject to section 5(2) of the Choice on Termination of Pregnancy Act which states that any female person of any age may consent to a termination of pregnancy by any medical or surgical means. Consent in these cases must, however, be informed consent ${ }^{22}$ and the child must be advised to consult with her parents or guardian. Consultation is, however, not a requirement of consent.

Section 134(1) prohibits any person from refusing to sell condoms to a child over the age of 12 years. Section 134(2) sets the lower limit at which contraceptives may be obtained at 12 years, with the additional requirement that the child must undergo a medical examination and be given proper medical advice. Section 130 provides that a child may consent to HIV testing at the age of 12 years and under the age of 12 , if he or she is mature enough to understand the benefits, risks and implications of testing. He or she can consent to the disclosure of the results of HIV testing at the age of 12 years.

Circumcision can only be performed if the child is over the age of 16 years with his consent. If the child is under the age of 16 years, circumcision can only be performed for medical or religious reasons. If the child is 12 years of age his consent is required. ${ }^{93}$ Section $12(4)$ and (5) prohibit virginity testing where the child is under the age of 16 years. It can be performed on a female child over the age 16 with her consent.

It is clear that the Children's Act regulates a variety of behaviours which may be connected to sexual development. The primary mechanism of regulation appears to be age. While age categorisation is a standard method to determine capacity and status, the variety of ages used in the Act, and its associated legislative regulations, are indicative that age in isolation is not as reliable as previously thought. The nature of the act consented to and the social circumstances of the child, as well as his or her level of development must be taken into account in order to reach a valid conclusion. The authors submit that the plethora of age categories confuses normal childhood sexual development and cater almost exclusively to sui generis situations. In addition, some of the age categories are illogical when viewed against the same test in the Sexual Offences Act - specifically sections 15 and 16 of that Act.

This submission centres on sexual development and practice in childhood. Resultantly criminal aspects become relevant. In this light the authors examine the provisions relating to criminal capacity hereunder in light of the fact that children may come into contact with the criminal justice system in light of their conduct under section 15 and 16 of the Sexual Offences Act.

practitioner has consulted with the child and confirmed that the procedure accords with the child's best interests. If the child is 12 years of age and sufficiently mature to understand the risks and benefits of the sterilisation, the child's consent is also required. This must however be seen in light of the fact that a child's unreasonable refusal may be overridden by the Minister of Social Development.

92 Christian Lawyers Association $v$ Minister of Health and Others (Reproductive Health Alliance as Amicus Curiae) 2005 (1) SA 509 (T) 516.

93 S 12(8)-(10) of the Children's Act. 


\section{Age and the Child Justice Act 75 of 2008}

A child can enter the criminal justice system as a result of his or her actions under section 15 or 16 of the Sexual Offences Act, albeit only under the discretion of the Director of Public Prosecution. Nonetheless, the logic of such a step must be considered against the criminal capacity of a child in South African criminal justice. In terms of section 7 of the Child Justice Act a child between the ages of 10 and 14 is considered rebuttably doli incapax. In these cases the child will be prosecuted only if he or she can be proved to understand the difference between right and wrong and found capable of acting in accordance with that appreciation. It seems almost naïve of the legislature to protect children under section 15 and 16 of the Sexual Offences Act, and to consider their consent valid if they are between the ages of 12 and 15, but then to question their criminal capacity if they are between the ages of 12 and 14 years of age. Likewise a child cannot be detained in prison if under the age of 14 years but, theoretically at least, may be prosecuted if there is more than a two-year age gap between sexual partners even where both parties consented to the act in question. It is clear the Child Justice Act is protective of the best-interest standard, but there is no clarity between protecting a child's best interests in any action taken against him or her, and judging the individual's own interpretation of his or her best interests when consenting to what is essentially little more than a private and intimate act.

\section{CONCLUSION}

In this submission we have attempted to show the importance of understanding children's sexuality. This, in our view, is important as it not only helps children understand and cope with changes inherent in their sexual development, but also minimises attempts to criminalize normal sexual behaviours. We are of the opinion that children, armed with better understanding of their sexuality, supported by informed adults, are empowered to make healthier choices regarding their sexual lives. Proper and consistent legal regulation of certain forms of conduct is, however, required in order to achieve this outcome. At present the multiple age categories relating to childhood sexuality and associate practices are creating a situation where a child cannot regulate his or her conduct with any degree of certainty. This, we aver, relates largely to categorising maturity on the basis of age alone and ignoring the child's cognitive and emotional development, as well as his or her bio-psycho-social environment and circumstances. In a rule of law state, laws are only legitimate if they are capable of being performed. In this case it is doubtful if children comprehend the variety of age based restrictions and categorisations outside of the Constitutional definition of childhood. In addition, the current legislative framework for regulating childhood sexuality is not consistent in its approach. If, for example, the child is pregnant versus medically ill the rules regarding the age of consent change. This reinforces law as a reactive instrument prepared to bend its definition of maturity in cases where the deed is done and the consequences must be dealt with, as opposed to providing proper mechanisms to ensure the protection of children 
undergoing normal sexual development. In addition, the current legal framework, as it pertains to sexual development, has neglected to consider the restrictions on autonomy in childhood. Amongst the Constitution, Children's Act and Sexual Offences Act the idea is reinforced that children can say no to sexual practices, but does not provide the same autonomy to consent to these acts. This situation imputes the idea that a child has the social, personal and legal power to refuse sex, but removes their agency to consent validly without potential criminal law consequences. There is no doubt that some children require guidance and support and often are not emotionally mature enough to consent to sexual intercourse, but the current law, by a strange twist, considers them mature enough to refuse. It is clear that the current legal framework requires children between the ages of 12 and fewer than 16 years to display the emotional maturity and development to refuse sex; but does not acknowledge these same characteristics when a child consents to the same act. 